\title{
Corrigendum: Two new species of the genus Dryopomorphus Hinton, 1936 from China (Coleoptera, Elmidae). ZooKeys 765: 5I-58. (2018). https://doi. org/l 0.3897/zookeys.765.24366
}

\author{
Dongju Bian', Xue Dong ${ }^{1,2}$, Yunfei Peng ${ }^{1,2}$
}

I CAS Key Laboratory of Forest Ecology and Management, Institute of Applied Ecology, Shenyang 110016, China 2 University of Chinese Academy of Sciences, Beijing, 100049, China

Corresponding author: Xue Dong (dx_dongxue@163.com)

Academic editor: Mariano Michat | Received 18 May 2019 | Accepted 20 May 2019 | Published 13 June 2019

http://zoobank.org/12B075F6-A9B8-4271-A0F5-949885F72BDF

Citation: Bian D, Dong X, Peng Y (2019) Corrigendum: Two new species of the genus Dryopomorphus Hinton, 1936 from China (Coleoptera, Elmidae). ZooKeys 765: 51-58. (2018). https://doi.org/10.3897/zookeys.765.24366. ZooKeys 855: 155-155. https://doi.org/10.3897/zookeys.855.36298

One school name needs to be corrected:

\section{Page 51:}

1 CAS Key Laboratory of Forest Ecology and Management, Institute of Applied Ecology, Shenyang, 110016, China.

2 Graduate University of Chinese Academy of Sciences, Beijing, 100039, China.

The correct one should be:

1 CAS Key Laboratory of Forest Ecology and Management, Institute of Applied Ecology, Shenyang, 110016, China.

2 University of Chinese Academy of Sciences, Beijing, 100049, China.

Copyright Dongju Bian et al. This is an open access article distributed under the terms of the Creative Commons Attribution License (CC BY 4.0), which permits unrestricted use, distribution, and reproduction in any medium, provided the original author and source are credited. 